\title{
Spontaneous and Therapy-induced T Cell Responses to Cancer
}

T. Blankenstein ${ }^{1,2}$

1 Director, Institute of Immunology, Charité Campus Benjamin Franklin, Berlin

${ }^{2}$ Max-Delbrück-Center for Molecular Medicine, Berlin

It has rarely been questioned that spontaneously occurring cancer cells have to escape T cell attack, even though this has not been directly demonstrated. Recently, it was shown that sporadic immunogenic cancer at the time of initial recognition induces an aberrant rather than a protective $T$ cell response, resulting in tolerance at the premalignant stage. Tumors which grew in the primary host despite initially functional tumor-reactive CTLs had a regressor phenotype upon transplantation. Thus, in a clinically relevant model, cancer cells do not need to escape. General CTL hyporesponsiveness is a late event, probably involves immature myeloid cells, requires immunogenic tumors, and appears to be a symptom, not the cause of tumor growth. Tumor-infiltrating lymphocytes reflect cancer-induced inflammation, rather than immunosurveillance. In contrast, tumors induced by virus infection induce an effective $T$ cell response and need to escape immunosurveillance by local tolerance. In contrast to endogenous $\mathrm{T}$ cells, adoptively transferred $\mathrm{T}$ cells have been shown to reject large established tumors. In such models, T cells recognize the tumor antigen as foreign. The task is to generate human T cell receptors (TCR) that recognize human tumor-associated (self) antigens as foreign and use these TCRs for gene therapy, which will facilitate clinical application.

\section{Conflict of Interest: None}

\section{Bibliography}

DOI http://dx.doi.org/10.1055/s-0032-1324903

Arzneimittelforschung 2012; 62, Suppl. 1: S9-S9

(c) Georg Thieme Verlag KG Stuttgart · New York .

ISSN 0004-4172

Please note that the print version was published with a different, incorrect DOI. The correct DOI is the one shown here. 